Organizational identification, work engagement, and job satisfaction

Maria Karanika-Murray, Nikita Duncan, Halley M. Pontes, and Mark D. Griffiths Nottingham Trent University, UK

This is a non-final version of an article published in final form in:

Karanika-Murray, M., Duncan, N., Pontes, H., \& Griffiths, M. (2015). Organizational identification, work engagement, and job satisfaction. Journal of Managerial Psychology. 


\begin{abstract}
Purpose: Organizational identification refers to a person's sense of belonging within the organization in which they work. Despite the importance of organizational identification in work-related attitudes and organizational behavior, little research has directly examined the mechanisms that link these. The aim of this study was to provide an understanding of how organizational identification relates to job satisfaction.

Design/methodology/approach: Adopting a social identity perspective, we present and test two models whereby work engagement and its constituent dimensions (vigor, dedication, andabsorption) mediate the relationship between organizational identification and job satisfaction.
\end{abstract}

Findings: Bootstrapped mediation analyses provided support for full mediation whereby there is an indirect (via work engagement) and positive effect of organizational identification on job satisfaction. Analyses also provided support for the mediating effects of the three dimensions of work engagement, vigor, dedication and absorption, in this relationship.

Research limitations/implications: Although cross-sectional, this study provides a needed first step towards an understanding of the important role of organizational identification for job satisfaction and the mediating role of work engagement in this relationship.

Originality/value: These results obtained provide valuable insights into the effects of organizational identification and address some of the gaps in understanding social identity as the context for work behaviors. Theoretical and practical implications for strengthening employee engagement and enhancing organizational identification are discussed. Keywords: organizational identification, social identity theory, work engagement, job satisfaction, mediation 


\section{Organizational identification, work engagement, and job satisfaction}

Describing a specific form of social identification and building on the social identity tradition, organizational identification is an important concept in research into affective and behavioral outcomes among employees (Mael \& Ashforth, 1992; Van Dick, 2004). Although organizational identification has been shown to yield desirable results for both organizations and individuals (Boroş, 2008), research on its relationship with work-related attitudes, such as job satisfaction, and on the mechanisms governing this relationship is in the very early stages of development. With job satisfaction being viewed by different stakeholders as a basic criterion of overall organizational functioning and performance (Gresov, Drazin, \& Van de Ven, 1989), a better conceptual understanding of how an employee's bond with the broader organization is linked to job satisfaction, and a more comprehensive view of the determinants of job attitudes is called for. The aim of this paper is therefore to examine the relationship between organizational identification on job satisfaction and to propose a mechanism accounting for this relationship. Specifically, drawing from Social Identity Theory, a model is presented whereby organizational identification is linked to job satisfaction through enhanced engagement with work. Empirical support for this model is offered and discussed along with implications for research and practice.

\section{Social identity, organizational identification and job satisfaction}

Social Identity Theory proposes that individuals' identities that stem from group membership are essential for their self-concepts (Tajfel \& Turner, 1979), which in turn impacts their affect, cognitions, and behavior (Abrams, 1996). Social identity is defined as 'that part of the individual's self-concept which derives from his [sic] knowledge of his [sic] membership in a social group (or groups) together with the value and emotional significance attached to that membership" (p. 63, Tajfel, 1978). Social Identity Theory provides the understanding that individuals can identify with a range of social categories based on gender, 
nationality, profession, and/or religion, among others, and that each of these can be the target of identification, alone or simultaneously. The theory has helped to substantially advance our psychosocial understanding of a range of phenomena related to social influence and group behavior including work-related activity.

Ashforth and Mael (1989) applied Social Identity Theory in the context of work organizations to define identification with a specific organization as a distinct target or entity, thus providing an alternative perspective for understanding organizational behavior and workrelated outcomes. As such, organizational identification is defined as "a psychological linkage between the individual and the organization whereby the individual feels a deep, self-defining affective and cognitive bond with the organization as a social entity" (Edwards \& Peccei, 2007, p.30) and "the degree to which a member defines him or herself by the same attributes that he or she believes define the organization" (Dutton et al., 1994, p.239). Similarly, Mael and Ashforth (1992) defined organizational identification as "the perception of oneness with or belongingness to an organization, where the individual defines him or herself in terms of the organization in which he or she is a member" (p. 104). The degree to which individuals feel part of - or identify with - the values and goals of the organization for which they work, is important for both individuals and their organizations (Boroş, 2008). For the organization, it has been proposed that organizational identification is essential for effective functioning (Fuller, Marler, Hester, Frey, \& Relyea, 2006). Individuals identify with a specific group in order to reduce uncertainty and gain desirable resources. In turn, these groups prescribe specific behaviors, attitudes and norms that the individual follows. Of course, one of the organization's most important tasks could be to maintain a positive and strong employment relationship by maintaining a strong identification among employees with their organization. Organizational identification is an important concept for understanding a range of work behaviors (van Dick, Hirst, Grojean, \& Wieseke, 2007) including turnover (van Knippenberg, 
van Dick, \& Tavares, 2005: Abrams, Ando, \& Hinkle, 1998), commitment (Cole \& Bruch, 2006), cooperation (Tyler \& Blader, 2001), and resistance to change (van Dijk \& van Dick, 2009).

For individuals, organizational identification provides a sense of identity and selfdefinition (Ashforth \& Mael, 1989; van Knippenberg \& Van Schie, 2000) whereby they define themselves with the organization as a social entity (Edwards \& Peccei, 2007). This can be considered as an affective and cognitive bond between the organization and the individual, where the individual's identity includes membership in the organization, thereby leading to a range of desirable attitudes and behaviors at work. The stronger an individual's identification with their organization, the more likely it is that they will act in accordance with the organization's goals and expectations (Dutton et al., 1994) and will be willing to stay with the organization (Reade, 2001). Additionally, because the wellbeing of the organization is in the interest of the individual, a lack of identification with the organization or work group may lead to discrepancies in goals and motivation, leading to reduced motivation and job satisfaction. Indeed the strong link between organizational and work group identification (on one hand) and job satisfaction and extra-role behavior (on the other), has been supported (van Dick, van Knippenberg, Kerschreiter, Hertel, \& Wieseke, 2008). Consistent with the literature, it is expected that this bond or self-definition influences individuals' attitude towards their job, and more specifically their job satisfaction. Therefore, our first hypothesis is:

Hypothesis 1: Organizational identification is positively related to job satisfaction

\section{Work engagement, organizational identification, and job satisfaction}

Social Identity Theory suggests that a strong bond between an employee and their organization reinforces their motivation to exert effort for (and on behalf of) their colleagues and their organization (Ashforth \& Mael, 1989; Dutton et al., 1994). In turn, a stronger 
psychological bond with a specific organization can also reinforce their willingness to perform better and to engage with work itself. Enhanced employee engagement can be both mental and physical, reflecting the attitudinal and behavioral elements of the concept. Bakker, Schaufeli, Leiter and Taris (2006) described engagement as "a positive, fulfilling affectivemotivational state of work-related well-being that is characterized by vigor, dedication, and absorption" (p. 187). Similarly, Kahn (1990) noted that "in engagement, people employ and express themselves physically, cognitively and emotionally during role performance" (p. 694). Although there is a debate as to whether work engagement is best viewed as a psychological state (attitude) or as a behavior (Newman, Dana, \& Hulin, 2010) and although it can be defined both attitudinally and behaviorally (Macey \& Schneider, 2008), for the purposed of the present study and in line with a strong literature, we view engagement as an affective-motivational state. Based on Social Identity Theory, and as discussed earlier, it can be expected that high identification with a specific organization will yield engagement with the organization's goals (i.e., the specific work and one's job role). An employee's psychological bond (or lack of it) with their organization can potentially enhance or undermine their engagement with their work.

There has been little (if any) published research on the direct link between work engagement and organizational identification, although Cartwright and Holmes (2006) called for research attention to the potential impact of meaningful work on engagement and identification. The organizational behavior literature supports a possible link between the two. Tyler and Blader (2001) showed that employees with strong group identification tend to have greater motivation to cooperative with their group, both directly and indirectly through the influence of identity on attitudes and values. Reade (2001) also showed that organizational identification directly predicts increased motivation and performing beyond an individual's core tasks. Individuals who have strong identification with their organization are more likely 
to be actively involved in its goals and activities, and therefore tend to be more motivated to work hard to achieve these goals (Dutton et al., 1994).

It can therefore be expected that individuals who have a strong psychological bond with their organization are likely to internalize their organization's aims and goals and therefore be more involved in achieving these goals by engaging with their work. Organizational identification will determine an individual's attitude towards their job, and specifically job satisfaction, by strengthening their engagement with work. Consequently, our second hypothesis is:

Hypothesis 2: Work engagement mediates the positive relationship between organizational identification and job satisfaction, such that organizational identification is positively related to work engagement which is, in turn, positively related to job satisfaction

Work engagement is seen as a higher-order construct that comprises several dimensions including vigor, dedication, and absorption in one's work (Bakker et al., 2008; Schaufeli, 2001; Schaufeli, Bakker, Van der Heijden, \& Prins, 2009; Schaufeli, Salanova, González-Romá, \& Bakker, 2002). Vigor refers to "high levels of energy and mental resilience while working, the willingness to invest effort in one's work, and persistence even in the face of difficulties", dedication is characterized by "being strongly involved in one's work and experiencing a sense of significance, enthusiasm, inspiration, pride, and challenge", whereas absorption refers to "being fully concentrated and happily engrossed in one's work, whereby time passes quickly and one has difficulties with detaching oneself from work" (Schaufeli, Bakker \& Salanova, 2006, p. 702). Engaged employees "have high levels of energy and mental resilience, are willing to invest effort, have persistence, are involved in their work, experience enthusiasm and pride, and identify strongly with their work" (Schaufeli \& Bakker, 2003). This three-factor model of work engagement and its relationship with workrelated outcomes such as job satisfaction and absenteeism have received strong empirical 
support (e.g., Schaufeli \& Bakker, 2004; Schaufeli, Bakker, \& van Rhenen, 2009). Although Schaufeli and Bakker (2010) have argued that an overall score of work engagement may be equally useful in empirical research, in order to fully understand how organizational identification affects engagement it is important to understand its relationships with the three specific dimensions.

Building on our second hypothesis, it is therefore suggested that a positive and strong psychological bond of oneness with the organization and internalization of its goals allows employees to be energized in their work and mentally resilient (vigor), to express perseverance and devotion to their work (dedication), and to engross themselves in their work (absorption), in turn, relating to higher satisfaction with their job. Consequently, our final hypothesis is:

Hypothesis 3: Vigor, dedication, and absorption mediate the positive relationship between organizational identification and job satisfaction, such that organizational identification is positively related to vigor, dedication, and absorption, which are, in turn, positively related to job satisfaction

\section{Method}

\section{Participants and Procedure}

In order to test the three research hypotheses, an online survey on the determinants of positive and negative work behaviors was distributed to employees in three UK organizations. All employees were invited to take part in the study and 194 returned completed questionnaires of which 177 had completed all measures and were therefore useable $(n=83$ [47\%] men and $\mathrm{n}=93$ [53\%] women; age $M_{\text {age }}=39$ years, range: $18-67$ years; tenure $M=$ 8.8 years, range: $<1-35$ years $)$. One-third of participants $(n=59)$ were responsible for managing others. Over one-third (39.0\%) were professionals (e.g., engineer, accountant, systems analyst), $35.6 \%$ provided clerical and administrative support (e.g., secretary, billing 
clerk, office supervisor), and $15.3 \%$ were executive or senior managers. The remaining $10.1 \%$ described their main role as technical support, sales, service occupation, operator or laborer. The right to withdraw at any time, confidentiality of the data, and anonymity of responses were explained to participants at the start of the survey.

\section{Measures}

Organizational identification was measured using Mael and Ashworth's (1992) 6-item measure that was designed to assess an individual's willingness to define themselves as a member of their organization. Respondents were asked to indicate their level of agreement with a range of items (e.g., "When someone criticizes [the organization], it feels like a personal insult", "This [organization's] successes are my successes", "When I talk about [the organization], I usually say 'we' rather than 'they'”) on a 5-point Likert scale (from $1=$ strongly disagree to $5=$ strongly agree). Previous research has reported good validity (Miller et al., 2000) and Cronbach's alpha reliability values ranging from .86 to .91 (Dukerich, Golden, \& Shortell, 2002; Bartels et al., 2007; Wisenfeld, Raghuram, \& Garud, 1999; Liberman, 2008) with $\alpha=.86$ for the present study.

Work engagement was assessed using the short version of the Utrecht Work Engagement Scale (UWES-9; Schaufeli, Bakker, \& Salanova, 2006). The UWES-9 comprises three subscales that reflect the underlying dimensions of vigor (3 items: e.g., "At my job, I feel strong and vigorous"), dedication (3 items: e.g., "I am enthusiastic about my job"), and absorption (3 items: e.g., "I am immersed in my work"). Participants were asked to indicate whether they had ever felt this way about their work on a 7-point Likert scale (from $0=$ never to $6=$ always). The measure has been shown to have good internal consistency ( $\alpha=.85$ to .92 ; Schaufeli et al., 2006) with the present study yielding $\alpha=.94$ for the overall work engagement scale and $\alpha=.87, .90$, and .74 for vigor, dedication, and absorption, respectively. 
In order to examine if the original three-factor solution for UWES-9 would fit the data, confirmatory factor analysis (CFA) was performed with maximum likelihood estimation method with robust standard errors (MLR) in MPLUS 6.1 (Muthén \& Muthén, 2011). Goodness of fit was evaluated using a $p$ value of Chi-square $<0.5$ for the test of close fit. Further fit indices included the Bentler comparative fit index (CFI), Tucker-Lewis fit index (TLI), root mean square error of approximation (RMSEA) and its 90\% confidence interval ( $90 \% \mathrm{CI}$ ), and standardized root mean square residual (SRMR). A CFI value of $>.90$ and an RMSEA value of $<.08$ are considered to reflect acceptable fit, whereas a CFI value of $>.95$ and an RMSEA value close to .06 are considered to reflect good model fit (Byrne, 2013; Hu $\&$ Bentler, 1999). The analysis of the first-order model of work engagement with the three factors (vigor, dedication, absorption) provided a good model fit for the IGD Test, $\chi^{2}(22, \mathrm{~N}=$ $158)=49.62, p=.00 ; \mathrm{CFI}=.96 ; \mathrm{TLI}=.94 \mathrm{RMSEA}=0.09(90 \% \mathrm{CI}: 0.06-0.12), p \mathrm{close}=.03$; $\mathrm{SRMR}=0.03$. All factor loadings were higher than .50 .

Job satisfaction was assessed with a composite measure of three items adapted from the Job Diagnostic Survey (Hackman \& Oldham, 1980) (e.g., "In general, my job measures up to the sort of job I wanted when I took it”). Respondents were asked to indicate how true the three statements were for them, on a 7-point scale (from $1=$ strongly disagree to $7=$ strongly agree). Cronbach's alpha for the present study was .85 .

Because managerial responsibility (i.e., responsibility for supervising others) and tenure can be conceptually associated with work engagement, they were included in the study as potential control variables. Tenure was assessed in number of years whereas managerial responsibility on a binary scale. However, neither these nor any of the demographic variables were associated with job satisfaction or the mediators and are therefore were not included in the subsequent analyses.

\section{Results}


Table 1 presents the means (M), standard deviations (SD), and zero-order Pearson correlations $(r)$ for the study variables and reliability coefficients (Cronbach's alpha) for all study variables. Consistent with Hypothesis 1, organizational identification (OID in the remainder of this section) was positively correlated with job satisfaction (JS, as above) $(r=$ $.39, p>.01)$. OID was also positively correlated with work engagement (WE, as above) $(r=$ $.50, p>.01)$. Moreover, WE was positively correlated with JS $(r=.63, p>.01)$. Similarly, vigor, dedication and absorption were positively correlated with OID $(r=.47, .46$, and .46, respectively, $p>.01)$ and JS $(r=.66, .66$, and $.44, p>.01)$.

[Insert Table 1 about here]

In order to examine the mediation hypotheses, two analyses were performed using the bootstrapping method as discussed in Preacher and Hayes (2004). This approach allows the computation of bootstrapped samples and bias-corrected and accelerated confidence intervals to test indirect effects of mediation. Preacher and Kelley’s (2011) Kappa-squared was also computed to ascertain the effect sizes of any indirect effects observed in the simple mediation model. Preacher and Hayes's (2004) approach is preferred over Baron and Kenny’s (1986) approach because of the latter's limitation concerning its sensitivity to normality deviations, usually requiring bigger samples sizes. Moreover, the former has increased power in comparison to older methodologies and is preferred over the Sobel test and even over SEM approaches to mediation for small sample sizes. All the analyses were carried out on IBM SPSS Statistics for Windows, Version 20 and PROCESS version 2.11 (Hayes, 2012). Prior to the analyses, all variables used in the models were checked for multicollinearity (by examining the Variation Inflation Factors) and no issues were detected since all VIF values were $<5$ and not beyond the threshold of 10 (Yan $\&$ Su, 2009). For both mediation models, total, direct, and indirect effects were obtained on the basis of 10,000 bootstrapped samples and bias-corrected and accelerated confidence intervals with 95\% level of confidence. 
One of the main advantages of bootstrapped mediation (Preacher \& Hayes, 2004) is that unlike the normal theory approach (e.g., Baron \& Kenny, 1982; Sobel, 1982), no assumption is made about the shape of the sampling distribution. Bootstrap confidence intervals better respect the irregularity of the sampling distribution of absorption and, as a result, yield inferences that are more likely to be accurate than when the normal theory approach is used. When used to test a hypothesis, the result is a test with higher power (Hayes, 2013).

Results from the simple regression performed to test Hypothesis 2 (see Figure 1) suggested that OID significantly predicted WE $(b=0.97, \mathrm{SE}=0.13, t=7.25, p<.0001)$, explaining $25.2 \%$ of the variance in $\mathrm{WE}\left(\mathrm{R}^{2}=.2520\right)$. Additionally, in the regression of WE and OID on JS, JS was only significantly predicted by WE $(b=024, \mathrm{SE}=0.03, t=8.49, p<$ $.0001)$ but not by OID $(b=0.08, \mathrm{SE}=0.06, t=1.41, p=.16)$. This latter model explained $42.6 \%$ of the variance in JS $\left(\mathrm{R}^{2}=.4262\right)$.

Furthermore, whilst the total effect of OID on JS was significant $(b=0.31 ; \mathrm{SE}=.06 ; t$ $=5.463 ; p<.0001)$, the direct effect was not $(b=0.08 ; \mathrm{SE}=.06 ; t=1.409, p=.16)$. The results on the indirect effect suggested that WE fully mediated the relationship between OID and JS $(b=0.2361, \mathrm{SE}=.06, \mathrm{BCa}$ CI95\% [0.151, 0.337]). This confidence interval does not contain zero and is also above zero, indicating that the indirect effect is positive and providing clear evidence that the indirect effect is positive to a statistically significant degree (Hayes, 2013). Finally, the meditating effect of WE was large $\left(\mathrm{K}^{2}=.30\right.$, BCa CI95\% $\left.[.205, .391]\right)$ (Preacher \& Kelley, 2011). Therefore, Hypothesis 2 was fully supported.

[Insert Figure 1 about here]

Results from the simple regression conducted to test Hypothesis 3 (see Figure 2) suggested that OID significantly predicted vigor $\left(b=0.36, \mathrm{SE}=0.05, t=6.85, p<.0001, \mathrm{R}^{2}\right.$ $=.2312)$, dedication $\left(b=0.33, \mathrm{SE}=0.05, t=6.77, p<.0001, \mathrm{R}^{2}=.2270\right)$, and absorption $(b$ 
$\left.=0.29, \mathrm{SE}=0.05, t=6.20, p<.0001, \mathrm{R}^{2}=.1979\right)$. In addition, the model with JS as an outcome when controlling for Vigor, Dedication, Absorption, and OID was significant $\left(F\left(\mathrm{df}_{1}\right.\right.$ $\left.\left.=4,000 ; \mathrm{df}_{2}=153,000\right), p<.0001, \mathrm{R}^{2}=.5188\right)$ and explained approximately $52 \%$ of the variance in JS. In this model, the standardized beta coefficient obtained for absorption was negative despite being significant. Contrary to expectations, absorption seems to be inversely linked to JS.

In support of a full mediation model (Little, Card, Bovaird, Preacher \& Crandall, 2007) as Hypothesis 3 stated, the results indicated that the direct effects did not reach statistical significance $(b=0.07 ; \mathrm{SE}=.05 ; t=1.334, p=.18)$. The total indirect effect was positive and significant $(b=-0.2460, \mathrm{SE}=.05, \mathrm{BCa} C \mathrm{C} 95 \%[0.161,0.350])$. The results regarding the analyses of the total and specific indirect effects support Hypothesis 3 on the mediating role of absorption $(b=-0.1121, \mathrm{SE}=.04, \mathrm{BCa} \mathrm{CI} 95 \%[-0.202,-0.049])$, vigor $(b=$ 0.1717, $\mathrm{SE}=.06, \mathrm{BCa} \mathrm{CI} 95 \%[0.072,0.305])$, and dedication $(b=0.1864, \mathrm{SE}=.07, \mathrm{BCa}$ CI95\% $[0.074,0.336])$ in the relationship between OID and JS.

Furthermore, bootstrap confidence intervals for pairwise comparisons between specific indirect effects were analyzed. These comparisons are based in the notion that confidence intervals that do not contain zero provide evidence that the two indirect effects are statistically different from each other, whereas a confidence interval that straddles zero supports the claim of no difference between the specific indirect effects (Hayes, 2013).

Accordingly, the point estimate of the difference between the specific indirect effects for vigor and dedication which is -0.0148 has an associated BCa CI95\% [-0.225, 0.184, Boot $\mathrm{SE}=0.1034]$ suggesting that these two indirect effects are not statistically different from each other. That is, the indirect effect of OID on JS through vigor is no different than the indirect effect through dedication. Moreover, the same is not true for comparisons of the indirect effects of vigor and absorption $(0.2838, \mathrm{BCa}$ CI95\% [0.1482, 0.4652], Boot SE $=0.0898)$ and 
dedication and absorption (0.2985, BCa CI95\% [0.1473, 0.5083], Boot SE = 0.0898). The present findings therefore supported Hypothesis 3 but only partially.

Further analyses of the strength of the indirect effects associated with each mediator variable independently (i.e., controlling for the remaining mediators) suggest that dedication (0.1864) was the strongest mediator of the relationship between OID and JS, followed by vigor (0.1717), and absorption (-0.1121). An associated significance test cannot be obtained and, therefore, the results are merely indicative of the strength of the indirect effects.

[Insert Figure 2 about here]

\section{Discussion}

Building on Social Identity Theory and on the notion of organizational identification, it was hypothesized that employees who see membership of their organization as consistent with their personal values and as part of their self-definition will be more engaged and also more satisfied with their work. The analyses confirmed all three of our hypotheses. Results showed organizational identification has a strong and positive effect on job satisfaction and corroborates the findings van Dick et al. (2008). Expanding on this, the effect of organizational identification on job satisfaction is transmitted through work engagement, and specifically vigor and dedication. Employees who have a strong and positive bond with their organization are also highly engaged in their work, energized in and dedicated to their work, deriving job satisfaction as a consequence. As Macey and Schneider (2008) assert, "true identity with work reflects an 'authenticity' that results in employees connecting with work and addressing difficult issues (i.e., the engagement behavior)... It is from the experience of being psychologically present in the work — that the work is a part of one's identity - that employee development and productivity follow" (p. 12). Our study substantiates this with empirical evidence. 
As expected, the results also showed absorption to be a significant mediator, albeit its effect in the mediation model was - unexpectedly - negative. It transpires that absorption may not always necessarily be good for employees. We have identified a number of possible explanations. First, employees who identify strongly with their organization and have high work engagement may also engross themselves strongly in negative aspects of their work as well as positive, and as a consequence, their job satisfaction may be lower. Indeed, Britt et al. (2005) indicate that individuals who are highly engaged at work are also more negatively affected by negative events encountered at work, and as a consequence may be more strongly affected by work-related stressors. As Sonnentag, Mojza, Binnewies and Scholl (2008) note, "probably because these events at work are more meaningful for highly engaged persons and because high absorption in one's work implies also that one is highly absorbed in stressful situations".

Second, individuals who are overly absorbed in their work may not be able to detach psychologically after work (Sonnentag et al., 2008). Absorption, especially under nondetachment conditions, may perhaps interfere with personal and social activities, therefore compromising general positive affect and overall job evaluations. Third, organizational identification may also support a stronger organizational culture of working harder, which may reinforce (and even institutionalize) excessive drive to work that may be signified by extreme - but also 'unhealthy' - absorption levels. Often, organizational pressures and uncertainty increase the need to show visible involvement and commitment with work. However, such commitment may be felt as an externally imposed pressure rather than be intrinsically driven, and be reflected in reduced job satisfaction. Similarly, job satisfaction will be lower when individuals' preferences do not match those externally demanded (Caldwell \& O'Reilly, 1990). A final possible explanation may be that, in some extreme cases, absorption into work may lead to addiction to work (cf. Griffiths \& Karanika-Murray, 2012) 
and there is evidence that workaholism and job satisfaction are negatively related (Burke \& MacDermid, 1999). The definition of absorption where "one has difficulties with detaching oneself from work" (Schaufeli, Bakker \& Salanova, 2006, p. 702) supports the possibility of such an interpretation. For our models to be of theoretical and practical significance, additional research is considered necessary to disentangle the contribution of work engagement and its dimensions to core job attitudes and evaluations.

As an original theoretical contribution of this study, work engagement was identified as a linchpin between individual identity and work attitudes. Identity helps the formation of attitudes. It does that by 'oiling the wheels' of action. As Dutton and Dukerich (1991) note, the notion of organizational identity is vital for understanding organizational action and employee engagement. Our model has shown that work engagement here is the connecting link. Alternatively, in linking organizational identification and work engagement it may be worthwhile to view them as the individual's relationship with their organization and the individual's relationship with their work. In essence, a strong bond between the employee and their organization is an important prerequisite for their bond with their work, and one that is strongly related to attitudinal and behavioral outcomes. The notion of work cannot be limited to the job but should necessarily consider the broader organization that provides the context to this job and individuals' work experiences (authors' reference, undisclosed) and where the individual views him or herself in this. It has been argued that "all jobs have a design that constitutes a context for their incumbents, and that design is embedded in a larger work context" (Johns, 2010). Here, an understanding of this context entails an understanding of an individual's bond with their organization. By suggesting that the bonds with one's work and the organization can determine important outcomes, this study offers a small step towards integrating organizational identification and work engagement research. 
It would be worthwhile to explore, in practical terms, what an employee's sense of organizational identity suggests for their motivation and behavior at work and how these can be promoted. In more practical terms, designing jobs that are meaningful to the individual would entail boosting engagement and identification (cf. Cartwright \& Holmes, 2006). Furthermore, designing workplaces that can support meaningful work and help individuals meet fundamental psychological needs (authors' reference, undisclosed) could further strengthen this essential link between organizational action and individual outcomes. As Cartwright and Holmes (2006) indicate, meaningful work is about a sense of self, the work itself, and a sense of balance between the two. The search for a sense of identity and meaning, sourced both as organizational membership and engagement with work, is a neglected but essential aspect of healthy work and as such can form the focus of practical interventions.

The concept of 'who I am' in relation to an employee's organization's goals and values provides the context that supports engagement and involvement in day-to-day work. In future research, an examination of different foci of an individual's sense of identity and different forms of identification could provide a more comprehensive picture of how this relates to work-related attitudes and behaviors. In a meta-analysis by Riketta and van Dick (2005), attachment and identification with the workgroup was found to be stronger than attachment and identification with the organization, possibly due to the more proximal nature of the workgroup. This highlights workgroup identification as a potentially strong predictor of work engagement and job satisfaction, and a contender for future research. Similarly, job embeddedness or an individual's attachment to their job (Halbesleben \& Wheeler, 2008) offers a more proximal construct which adds to the sense of work-related identity and could therefore be further explored in relation to work engagement and job satisfaction. Such different foci of identification could also usefully be translated into effective practice. Indeed, increasing employee identification should not be based on implementing 'global and 
unspecific measures' (Van Dick, 2004), but rather, interventions should be designed to correspond to the specific dimension of identification that is the target of change. Finally, an alternative approach where the 'voices' of employees are explored qualitatively would offer the potential to supplement quantitative data and an avenue for future research. Such rich ideographic data would offer a different perspective to examining personal and sensitive issues that a quantitative approach cannot offer.

\section{Limitations}

One of the main limitations of this study is its relatively small sample size, which would not support a multilevel approach. Because individual employees are nested in work groups and organizations, and because individuals working in the same workgroup or organization are likely to be similar in their levels of organizational identification, a larger number of individuals and - more importantly - workgroups would have permitted a multilevel approach to be taken. Nevertheless, individuals also differ in their personal experiences and evaluations of variables that can be seen as residing at the organizational level. Although a multilevel approach was not possible in this study, we believe that its findings hold promise for understanding the role of organizational identification for job satisfaction, both theoretically and in practical terms.

A second limitation of this study is its correlational nature. Although the data did not allow for causal effects to be tested empirically, our hypotheses were firmly grounded in the assumptions and predictions of Social Identity Theory and organizational identification. Thus, our findings present a concrete theoretically-grounded explanatory step in establishing links between organizational identification and employee attitudes and behaviors. Future research should examine the temporal order and causal direction between the constructs (e.g., reverse causation or reciprocal effects), explore whether these relationships persist the longer term, and explore links with behavioral data such as performance. 
In addition, some may consider the use of self-report measures on a modestly sized target population as potential limitations. Self-reports are appropriate for 'private events' (Conway \& Lance, 2010; also see Howard, 1994) because it is the respondents themselves who are aware of their sense of identity, their feelings towards their job, and their sense of engagement with their work. Consideration of other-source data would induce bias. In terms of measurement errors induced by self-report, Conway and Lance (2010) identify and demystify three misconceptions about common method variance (we refer the reader to their work) and suggests that "misconceptions about common method bias have been perpetuated". We do not identify self-report or common method variance as an inherent bias in this study.

\section{Conclusions}

The experience of being a member of a specific organization and prescribing to its values and goals is linked to employee work-related cognitions, attitudes, and behaviors. More specifically, their sense of being focused, integrated, and connected (i.e., being engaged in their work). Grounded in Social Identity Theory, this study sought to ascertain employee engagement as an essential link between identification with an individual's organization and satisfaction in their job. A range of important theoretical and practical implications ensue, offering avenues for intervention, research, and conceptual development. These findings contribute with new knowledge to the organizational literature whilst also bringing new challenges for future research in this field. Employees' psychological bond with their organization can undermine or enhance their engagement in and satisfaction with their work.

\section{References}

Abrams, D., Ando, K. and Hinkle, S. (1998), "Psychological attachment to the group: Crosscultural differences in organizational identification and subjective norms as predictors of workers' turnover intentions", Personality and Social Psychology Bulletin, Vol. 24 No. 10, pp. 1027-1039. 
Ashforth, B. E. and Mael, F. (1989), "Social Identity Theory and the organization”, Academy of Management Review, Vol. 14 No. 1, pp. 20-39.

Bakker, A. B, Schaufeli, W. B., Leiter, M. P. and Taris, T. W. (2008), "Work engagement: An emerging concept in occupational health psychology", Work and Stress, Vol. 22 No. 3, pp. 187-200.

Baron, R. M. and Kenny, D. A. (1986), "The moderator-mediator variable distinction in social psychological research: Conceptual, strategic, and statistical considerations", Journal of Personality and Social Psychology, Vol. 51, pp. 1173-1182.

Boroş, S. (2008), “'Organizational identification: Theoretical and empirical analyses of competing conceptualizations", Cognitie, Creier, Comportament [Cognition, Brain, Behavior], Vol. 12 No. 1, pp. 1-27.

Burke, R. J. and MacDermid, G. (1999), “Are workaholics job satisfied and successful in their careers?", Career Development International, Vol. 4, No. 5, pp. 277-282.

Byrne, B. M. (2013), “Structural Equation Modeling with AMOS: Basic Concepts, Applications, and Programming”, New York, NY: Routledge.

Caldwell, D. F. and O'Reilly, C. A. (1990), "Measuring person-job fit with a profile comparison process", Journal of Applied Psychology, Vol. 75, pp. 648-657.

Cartwright, S. and Holmes, N. (2006), "The meaning of work: The challenge of regaining employee engagement and reducing cynicism”, Human Resource Management Review, Vol. 16, pp. 199-208.

Cole, M. S. and Bruch, H. (2006), "Organizational identity strength, identification, and commitment and their relationships to turnover intention: Does organisational hierarchy matter?" Journal of Organizational Behavior, Vol. 27, pp. 585-605. 
Conway, J. M. and Lance, C. E. (2010), "What reviewers should expect from authors regarding common method bias in organizational research" Journal of Business and Psychology, Vol. 25, pp. 325-334.

Dutton, J. E. and Dukerich, J. M. (1991), “Keeping an eye on the mirror: Image and identity in organizational adaptation”, Academy of Management Journal, Vol. 34 No. 3, pp. $517-554$.

Dutton, J. E., Dukerich, J. M. and Harquail, C. V. (1994), “Organizational images and member identification”, Administrative Science Quarterly, Vol. 39, pp. 239-263.

Edwards, M. R. and Peccei, R. (2007), “Organizational identification: Development and testing of a conceptually grounded measure", European Journal of Work and Organizational Psychology, Vol. 16 No. 1, pp. 25-57.

Fuller, J. B., Marler, L. E., Hester, K., Frey, L. and Relyea, C. (2006), “Construed external image and organizational identification: A test of the moderating influence of need for self-esteem", Journal of Social Psychology, Vol. 146 No. 6, pp. 701-716.

Gresov, C., Drazin, R. and Van de Ven (1989), “Work-unit task uncertainty, design and morale", Organization Studies, Vol. 10 No. 1, pp. 45-62.

Griffiths, M. D. and Karanika-Murray, M. (2012), “Contextualising over-engagement in work: Towards a more global understanding of workaholism as an addiction", Journal of Behavioral Addiction, Vol 1 No.3, pp. 87-95.

Hackman, J. R. and Oldham, G. R. (1980), Work Redesign, Addison-Wesley, Reading.

Halbesleben, J. R. B. and Wheeler, A. R. (2008), “The relative roles of engagement and embeddedness in predicting job performance and intention to leave", Work and Stress, Vol. 22 No. 3, pp. 242-256. 
Hayes, A. F. (2012), “PROCESS: A versatile computational tool for observed variable mediation, moderation, and conditional process modeling" [White paper], retrieved from http://www.afhayes.com/public/process2012.pdf

Hayes, A. F. (2013), "Introduction to mediation, moderation, and conditional process analysis: Methodology in the Social Sciences”, Guilford Press, Kindle Edition.

Howard, G. S. (1994), “Why do people say nasty things about self-reports?”, Journal of Organizational Behavior, Vol. 15, pp. 399-404.

Hu, L. T. and Bentler, P. M. (1999), "Cutoff criteria for fit indexes in covariance structure analysis: Conventional criteria versus new alternatives", Structural Equation Modeling: A Multidisciplinary Journal, Vol. 6 No. 1, pp. 1-55.

Johns, G. (2010), "Some unintended consequences of job design”, Journal of Organizational Behavior, Vol. 31, pp. 361-369.

Little, T. D., Card, N. A., Bovaird, J. A., Preacher, K. J. and Crandall, C.S. (2007), "Structural equation modelling of mediation and moderation with contextual factors", in Little, T.D., Bovaird, J.A. and Card, N.A. (Eds), Modelling Contextual Effects in Longitudinal Studies, Lawrence Erlbaum Associates, Mahwah, NJ, pp. 207-230.

Macey, W. H. and Schneider, B. (2008), “The meaning of employee engagement”, Industrial and Organizational Psychology, Vol. 1, pp. 3-30.

Mael, F. A. and Ashforth, B. E. (1992), “Alumni and their alma mater: A partial test of the reformulated model of organizational identification", Journal of Organizational Behaviour, Vol. 13, pp. 103-123.

Mael, F. A. and Ashforth, B. E. (1992), “Loyal from day one: Biodata, organizational identification and turnover among newcomers", Personnel Psychology, Vol. 48, pp. $307-333$. 
Muthén, L. K. and Muthén, B. O. (2011), “Mplus User's Guide”, Los Angeles, CA: Muthén \& Muthén.

Newman, D. A., Dana, L. J. and Hulin, C. L. (2010), “Job attitudes and employee engagement: Considering the attitude 'A-factor'", Albrecht S., The handbook of employee engagement: Perspectives, issues, research and practice, Edward Elgar, Cheltenham, UK, pp. 43-61.

Preacher, K. J. and Hayes, A. F. (2004), "SPSS and SAS procedures for estimating indirect effects in simple mediation models", Behavior Research Methods, Instruments, and Computers, Vol. 36, pp. 717-731.

Preacher, K. J. and Kelley, K. (2011), "Effect size measures for mediation models: Quantitative and graphical strategies for communicating indirect effects", Psychological Methods, Vol. 16, pp. 93-115.

Reade, C. (2001), “Antecedents of organizational identification in multinational corporations: Fostering psychological attachment to the local subsidiary and the global organisation", International Journal of Human Resource Management, Vol. 12 No. 8 , pp. 1269-1291.

Riketta, M. and van Dick, R. (2005), "Foci of attachment in organizations: A meta-analytic comparison of the strength and correlates of workgroup versus organizational identification and commitment", Journal of Vocational Behavior, Vol. 67, pp. 490510.

Schaufeli, W. B. and Bakker, A. B. (2004), "Job demands, job resources, and their relationship with burnout and engagement: A multi-sample study", Journal of Organizational Behavior, Vol. 25, pp. 293-315. 
Schaufeli,W. B., Bakker, A. B. and van Rhenen, W. (2009), "How changes in job demands and resources predict burnout, work engagement, and sickness absenteeism", Journal of Organizational Behavior, Vol.30, pp. 893-917.

Schaufeli, W. B., Bakker, A. B. and Salanova, M. (2006), "The measurement of work engagement with a short questionnaire: A cross-national study”, Psychological Measurement, Vol. 66 No. 4, pp. 701-716.

Schaufeli, W. B., Bakker, A. B., Van der Heijden, F. M. M. A. and Prins, J. T. (2009), "Workaholism among medical residents: It is the combination of working excessively and working compulsively that counts", International Journal of Stress Management, Vol. 16, pp. 249-272.

Schaufeli, W. B., Salanova, M., González-Romá, V. and Bakker, A. B. (2002),” The measurement of engagement and burnout: A two sample confirmatory factor analytic approach", Journal of Happiness Studies, Vol. 3, pp. 71-92.

Sobel, M. E. (1982), “Asymptotic confidence intervals for indirect effects in structural equation models”, Leinhardt S., Sociological Methodology, American Sociological Association, Washington, DC, pp. 290-312.

Sobel, M. E. (1988), “Direct and indirect effects in linear structural equation models”, Long J. S., Common Problems/Proper Solutions, Sage, Beverly Hills, CA, pp. 46-64.

Sonenntag, S., Mojza, E. J., Binnewies, C. and Scholl, A. (2008), "Being engaged at work and detached at home: A week-level study on work engagement, psychological detachment, and affect", Work and Stress, Vol. 22 No. 3, pp. 257-276.

Tabachnick, B.G. and Fidell, L.S. (2001), Using Multivariate Statistics, Harper Collins, NY. Tajfel, H. (1978), “Social categorization, social identity and social comparison”, Tajfel H., Differentiation Between Social Groups: Studies in the Social Psychology of Intergroup Relations, Academic Press, London, pp. 61-76. 
Tajfel, H. and Turner, J. C. (1979), “An integrative theory of intergroup conflict”, Austin W.G. and Worchel S., The Social Psychology of Intergroup Relations, Brooks/Cole, Monterey, CA, pp. 33-47.

Tyler, T. R. and Blader, S. L. (2001), "Identity and cooperative behavior in groups", Group Processes Intergroup Relations, Vol. 4 No. 3, pp. 207-226.

van Dick, R. (2004), “My job is my castle: Identification in organizational contexts”, Cooper C. L. and Robertson I. T., International Review of Industrial and Organizational Psychology, Wiley, Chichester, Vol. 19, pp. 171-204.

van Dick, R., van Knippenberg, D., Kerschreiter, R., Hertel, G. and Wieseke, J. (2008), “Interactive effects of work group and organizational identification on job satisfaction and extra-role behaviour", Journal of Vocational Behavior, Vol. 72, pp. 388-399.

van Dijk, R. and van Dick, R. (2009), "Navigating organizational change: Change leaders, employee resistance and work-based identities", Journal of Change Management, Vol. 9, pp. 143-163.

van Knippenberg, D., van Dick, R. and Tavares, S. (2005), “Social identity and social exchange: Identification, support, and withdrawal from the job", ERIM Report Series Research in Management (ERS-2005-093-ORG), Erasmus Research Institute of Management (ERIM), Erasmus University, Rotterdam, the Netherlands.

van Knippenberg, D. and van Schie, E.C.M. (2000), "Foci and correlates of organizational identification", Journal of Occupational and Organizational Psychology, Vol. 73, pp. $137-147$.

Yan, X. and Su, X. (2009), Linear regression analysis: Theory and computing, World Scientific Publishing, London. 
Table 1 Means, Standard Deviations, Correlations and Reliability Coefficient for Study Variables

\begin{tabular}{|c|c|c|c|c|c|c|c|c|c|c|c|c|}
\hline & $\mathrm{M}$ & $\mathrm{SD}$ & 1 & 2 & 3 & 4 & 5 & 6 & 7 & 8 & 9 & 10 \\
\hline 1. Age & 39.48 & 11.51 & & & & & & & & & & \\
\hline 2. Gender & 1.53 & .50 & -.07 & & & & & & & & & \\
\hline 3. Managerial responsibility & .34 & .47 & $.16^{*}$ & $-.18 * *$ & & & & & & & & \\
\hline 4. Tenure & 8.77 & 8.37 & $.52 * *$ & -.09 & $.19 * *$ & & & & & & & \\
\hline 5. Organizational identification & 24.62 & 5.73 & .12 & $-.16^{*}$ & $.25^{* *}$ & .10 & $(.86)$ & & & & & \\
\hline 6. Work engagement & 47.46 & 11.06 & -.04 & .04 & .11 & -.12 & $.50 * *$ & $(.94)$ & & & & \\
\hline 7. Vigor & 14.71 & 4.23 & -.00 & -.02 & .07 & $-.14^{*}$ & $.46^{* *}$ & $.93^{* *}$ & $(.87)$ & & & \\
\hline 8. Dedication & 16.21 & 3.98 & -.06 & .04 & .12 & -.10 & $.46^{* *}$ & $.94 * *$ & $.84 * *$ & $(.90)$ & & \\
\hline 9. Absorption & 16.54 & 3.75 & -.03 & .08 & .12 & -.08 & $.46^{* *}$ & $.90 * *$ & $.76^{* *}$ & $.81 * *$ & $(.74)$ & \\
\hline 10. Job satisfaction & 15.30 & 4.62 & -.03 & .09 & -.04 & -.03 & $.39 * *$ & $.63^{* *}$ & $.66^{* *}$ & $.66^{* *}$ & $.44 * *$ & (.88) \\
\hline
\end{tabular}

Note: $\mathrm{N}=177 . * p>.05, * * p>.01, * * * p>.001$, one-tailed. Cronbach's alphas are indicated on the diagonal 


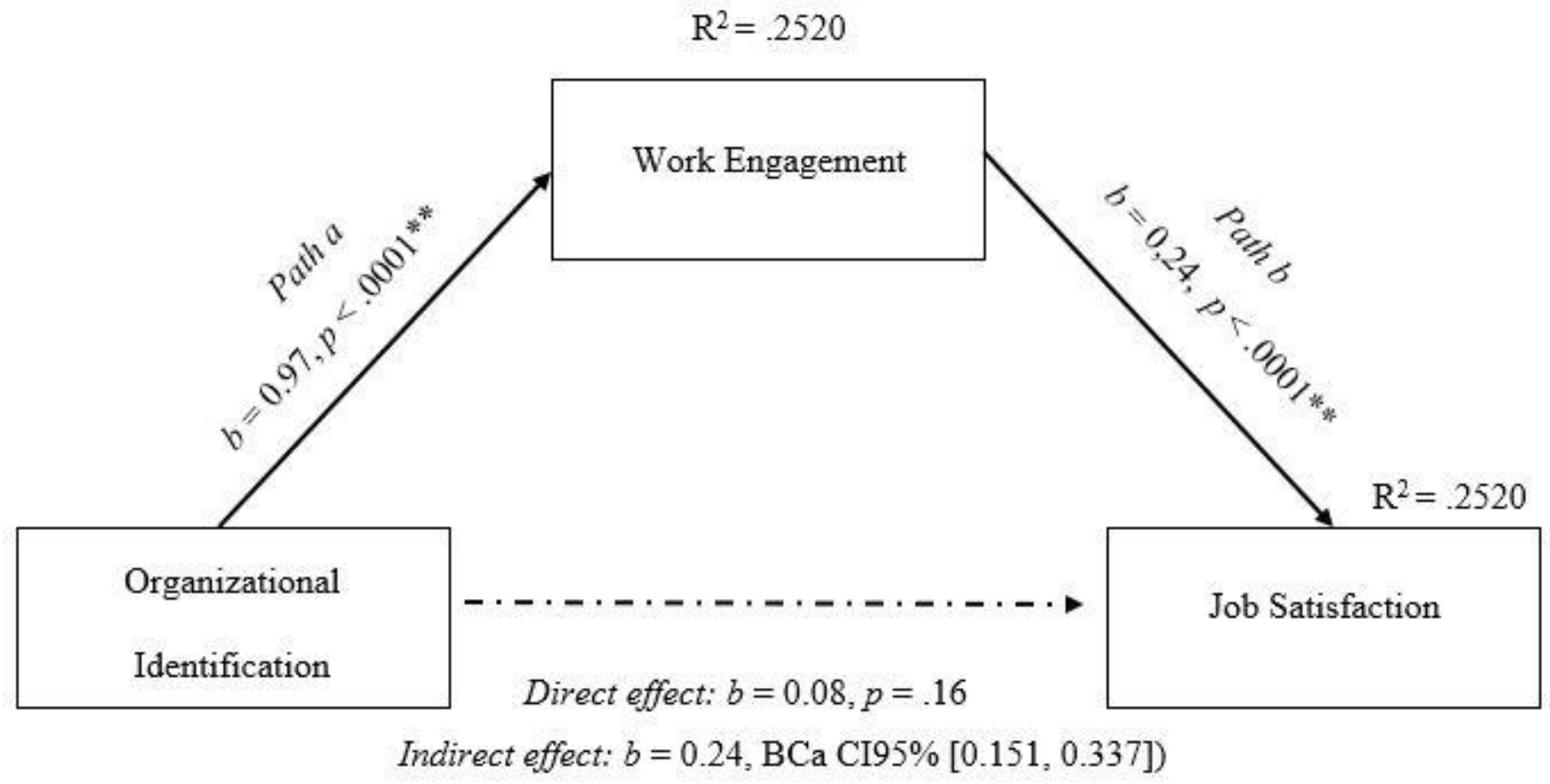

Figure 1. The overall mediation model with standardized beta path coefficients and their explained variance $\left(\mathrm{R}^{2}\right)$ for the outcomes $(\mathrm{N}=158)$. Note: Mediation performed using $\mathrm{BCa}$ bootstrapped $95 \%$ confidence intervals based on 10.000 samples; Simple arrows: significant path coefficients, dotted arrows: nonsignificant path coefficients. ${ }^{*} \mathrm{p}<0.05 ;{ }^{* *} \mathrm{p}<0.01$. 


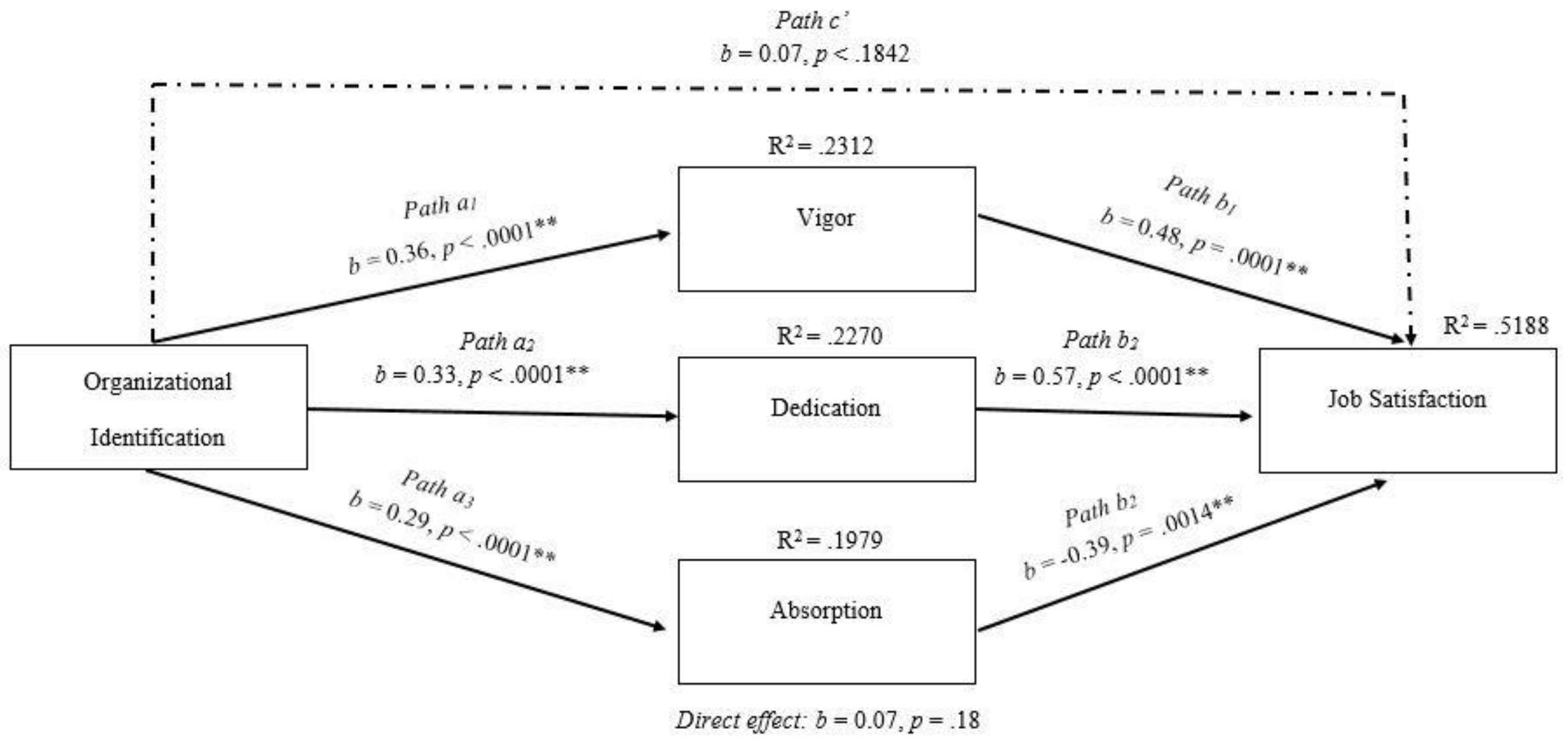

Figure 2. The overall mediation model with standardized beta path coefficients and their explained variance $\left(\mathrm{R}^{2}\right)$ for the outcomes $(\mathrm{N}=158)$. Note: Mediation performed using BCa bootstrapped $95 \%$ confidence intervals based on 10.000 samples; Simple arrows: significant path coefficients, dotted arrows: non-significant path coefficients. * $\mathrm{p} \leq 0.05$; ${ }^{* 8} \mathrm{p}<0.01$. 